\title{
Chronic localized back pain due to entrapment of cutaneous branches of posterior rami of the thoracic nerves (POCNES): a case series on diagnosis and management
}

This article was published in the following Dove Medical Press journal: Journal of Pain Research

\author{
Robbert C Maatman' \\ Oliver B Boelens ${ }^{2}$ \\ Marc RM Scheltinga' \\ Rudi MH Roumen' \\ 'SolviMáx, Center of Expertise \\ for ACNES, Center of Excellence \\ for Chronic Abdominal Wall and \\ Groin Pain, Department of Surgery, \\ Máxima Medical Center, Veldhoven, \\ The Netherlands; ' ${ }^{2}$ Department of \\ Surgery, Maasziekenhuis Pantein, \\ Boxmeer, The Netherlands
}

\begin{abstract}
Introduction and aim: Chronic back pain (CBP) may be caused by a variety of conditions including dysfunctional muscles, ligaments or intervertebral discs, improper movement of vertebral column joints, or nerve root compression. Recently, CBP was treated successfully in a patient having an entrapment of cutaneous branches of the posterior rami of the thoracic nerves, termed posterior cutaneous nerve entrapment syndrome (POCNES). Our aim is to describe clinical presentation, differential diagnosis, and management of patients with such a neuropathic pain syndrome. Methods: This study analyzed prospectively obtained data from consecutive patients suspected of having POCNES, presenting to two Dutch hospitals between January 2013 and September 2016. Patients received a diagnostic $2-5 \mathrm{~mL} 1 \%$ lidocaine injection just below the thoracolumbar fascia. Pain was scored using a numerical rating scale $(0=$ no pain to $10=$ worst possible pain $)$. A $>50 \%$ pain reduction was defined as success. A neurectomy was proposed if pain reduction was temporary or insufficient after one to three injections. Long-term treatment effect was determined using a verbal rating scale (VRS; 1 = very satisfied, no pain, to $5=$ pain worse).

Results: Fourteen patients (12 women, median age 26, age range 18-73) were diagnosed with POCNES. Eighty-one percent $(n=11)$ reported a $>50 \%$ pain drop after injection (NRS pain scores of median 8.0 [IQR 7.0-8.0] to median 3.0 [IQR 1.5-3.5], $P<0.001$ ). In one patient, repeated injections were successful long-term (VRS score of 2). Two patients declined surgery, whereas the remaining eleven underwent a neurectomy that was successful in seven (64\%). A 57\% long-term efficacy (median 29 months follow-up, range 5-48, VRS score 1-2) was attained in the entire study population.
\end{abstract}

Conclusion: POCNES should be considered in the differential diagnosis of chronic localized back pain. A treatment regimen including injections and neurectomy of the specific cutaneous branch results in long-term pain relief in more than half of these patients.

Keywords: chronic pain, neuropathic pain, chronic back pain, nerve entrapment

\section{Introduction}

Approximately $80 \%$ of the global population will experience acute lower back pain at some point in life, and 5\%-10\% will go on to develop chronic back pain (CBP) resulting in a major health burden. ${ }^{1-3} \mathrm{CBP}$ may be due to mechanical dysfunctioning, a neuropathic disorder, or secondary to other conditions while the differential diagnosis is extensive. ${ }^{4-8} \mathrm{CBP}$ often requires a multimodal treatment stratagem, but pain relief in the long term is often suboptimal. , $^{5,10}$
Correspondence: Robbert C Maatman SolviMáx, Center of Expertise for ACNES, Center of Excellence for Chronic Abdominal Wall and Groin Pain, Department of Surgery, Máxima Medical Center, P.O. Box 7777, 5500 MB Veldhoven, The Netherlands

Tel +3I 408886230

Email solvimax.resurge@mmc.nl 
A recent case report attracted attention to a novel syndrome causing CBP termed posterior cutaneous nerve entrapment syndrome (POCNES). ${ }^{11}$ This condition is supposedly due to irritation of cutaneous branches of the posterior rami of the thoracic spinal nerves by an unknown cause. The patient reported a neuropathic pain that was accompanied by sensations such as localized hyperalgesia and allodynia. ${ }^{12,13}$ The differentiation between neuropathic and nonneuropathic pain is always challenging, but neuropathic signs and symptoms may be suspected during extensive history taking using specific questionnaires suggesting neuropathic pain such as Douleur Neuropathique 4 (DN4), or following simple tests during physical examination. ${ }^{14-16}$ Ultimately, a simple neurectomy abolished the severe pain that had bothered her for years. While the number of studies on a localized neuropathic anterior abdominal pain (anterior cutaneous nerve entrapment syndrome [ACNES]) is steadily increasing, chronic localized (lower) back pain that is caused by an entrapped cutaneous branch of the posterior ramus of the thoracic spinal nerve is thought to be a new phenomenon and not yet known to the medical community.

The department of General Surgery/SolviMáx has gained ample expertise in the management of neuropathic pain syndromes of the trunk including ACNES. ${ }^{17,18}$ This abdominal wall pain syndrome is possibly caused by the entrapment of anterior cutaneous branches of thoracoabdominal intercostal nerves at a specific point of the ventral portions of the abdomen. These nerves are usually anchored at three sites: 1) at the back where the posterior branches of the thoracic nerve originate, 2) at the flank where the lateral branch originates, and 3) at the anterior abdominal wall where the nerve enters the rectus abdominis muscle (Figure 1). ${ }^{19}$ A previously mechanical theory suggested that a too tight anchor may cause ischemia and severe pain at any of these three locations. ${ }^{20}$

Aim of our study is to describe a series of CBP patients who were diagnosed and treated for possible entrapment of cutaneous branches of the posterior rami of the thoracic spinal nerves POCNES. Awareness regarding this unknown condition may thus be increased.

\section{Methods}

\section{Setting}

This prospective case series was conducted at Departments of General Surgery of two Dutch hospitals, Pantein Hospital, Boxmeer and Máxima Medical Center, Eindhoven/Veldhoven, between January 2013 and December 2016. Surgeons of both centers have a special interest in the management of chronic pain syndromes of abdominal wall and groin..$^{18,21,22}$ Both local ethics committees of the two participating hospitals approved the study protocol and decided that the Medical Research Involving Human Subjects Act [Wet maatschappelijke ondersteuning] did not apply (N17.009). The present analysis was considered auditing of results and evaluation of patient-reported outcomes. All patient data were anonymized. The present study follows guidelines of the Declaration of Helsinki (version October 19, 2013).

\section{Patient assessment}

After a letter of referral including history, earlier physical examinations, laboratory testing, and imaging that were performed elsewhere is screened by one of three senior surgeons (OB, MS, and RR) skilled in the management of abdominal wall and groin pain, a patient is invited to undergo an outpatient assessment in one of the two hospitals. An outpatient evaluation is started with an extensive history taking, focusing on aspects of pain including provocative movements and earlier therapies, as well specifically on neuropathic pain (DN4). ${ }^{23}$ Physical examination includes a series of standard tests. ${ }^{24,25}$ The patient is asked to indicate the location of maximum pain. Skin tactile sensibility and sensitivity to cold was tested using a cotton swab and an alcohol soaked gauze to detect somatosensory disturbances such as hypoesthesia, hyperesthesia, and/or altered cool perception in proximity of the painful area. Furthermore, "pinching" the skin overlying the painful area using thumb and index finger is often painful in comparison to the contralateral side. This phenomenon is called a positive pinch test and is suggestive of neuropathic pain. ${ }^{24,26}$ Local pressure on the specific tender point may also result in a disproportionally painful response.

While most of these patients are referred for evaluation of a chronic abdominal or groin pain, small subsets were found to have pain located at the flank, or at the back. ${ }^{11,25}$ Therefore, inclusion criteria for the diagnosis POCNES are based on a large (but subjective) experience in patients with ACNES and lateral cutaneous nerve entrapment syndrome (LACNES). ${ }^{17,25}$ Patients aged $>18$ were eligible for inclusion in the present case series if at least four out of five the criteria shown in Box 1 were met. Absence of objective abnormalities in either laboratory testing or imaging techniques as earlier determined in the referring hospital confirmed a cause for CBP other than a mechanical cause (eg, degenerative thoracolumbar disease) or a referred pain from visceral disease (eg, kidney stones). Results of history and physical examination were tabulated in a standard outpatient evaluation form and were stored in the hospital's electronic patient file. 


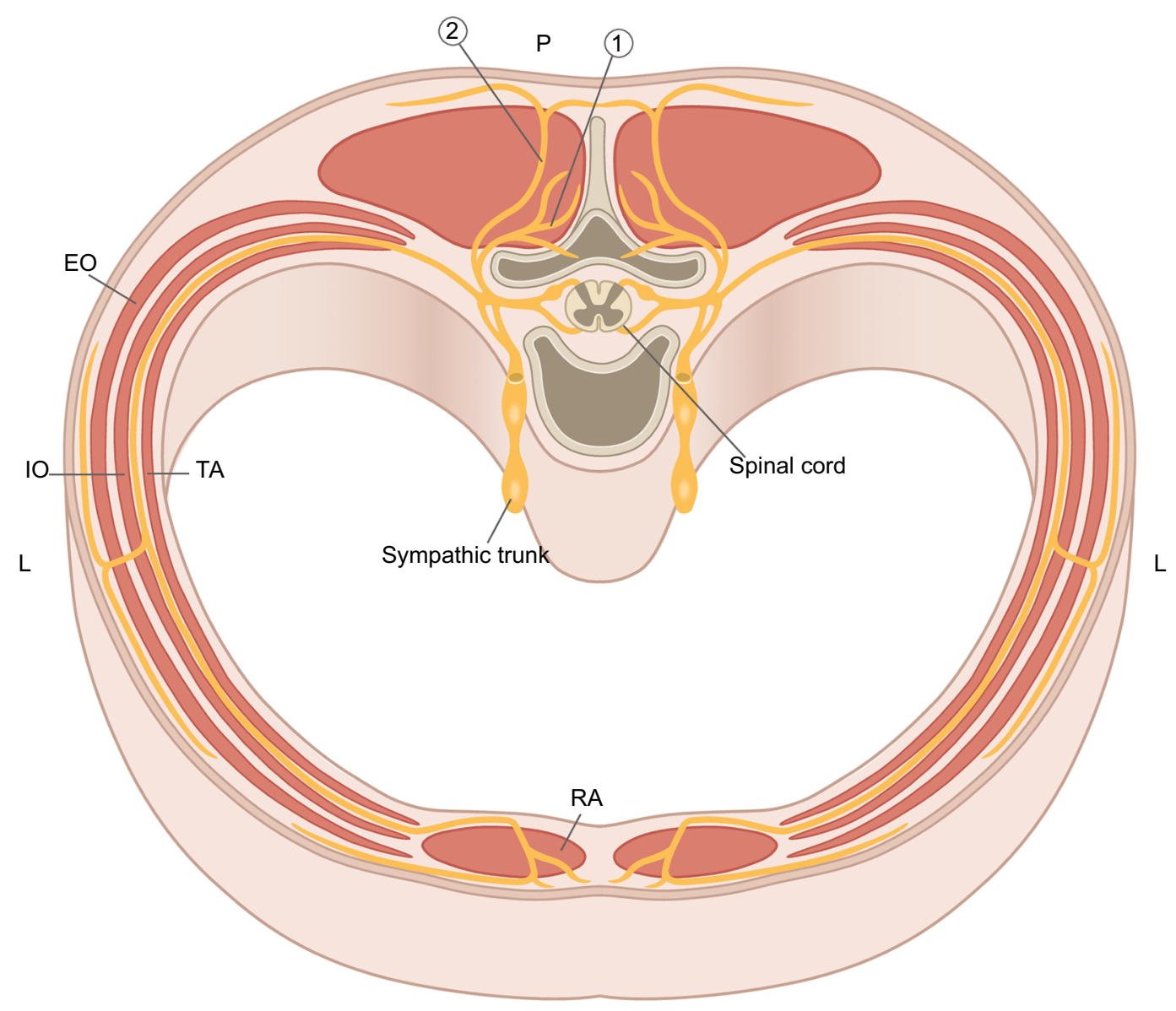

A

Figure I Anatomy of a thoracic spinal nerve with the intercostal cutaneous nerve originating from ventral ramus. The posterior ramus divides in a medial (articular) branch (I) and the cutaneous branch of the posterior ramus of the thoracic spinal nerve (2). The group of muscles pictured lateral of the spinous process are the erector spinae muscle.

Abbreviations: A, anterior; EO, external oblique muscle; IO, internal oblique muscle; L, lateral; P, posterior; RA, rectus abdominis muscle; TA, transverse abdominal muscle.

Box I Inclusion and exclusion criteria for posterior cutaneous nerve entrapment syndrome (POCNES)

Inclusion criteria

I) A >3-month history of locoregional back pain

2) A localized circumscript area of tenderness lateral to the spinous process, covering a small and predictable point of maximal pain

3) A larger area of skin somatosensory abnormalities (such as hypoesthesia, hyperesthesia, and/or altered cool perception) overlying this maximal pain point

4) Local pressure on the tender point resulting in a predictable severe pain response

5) Normal laboratory testing and imaging

\section{Exclusion criteria}

I) Surgical scar-related pain syndromes

2) Previous spinal surgical procedures at or between vertebral levels T7-LI

3) Impaired communication

\section{Current management}

If patients met at least four of five diagnostic criteria as shown in Box 1, a presumptive diagnosis of POCNES was communicated and specifics of a diagnostic injection of an anesthetic agent were discussed. After informed consent was obtained, patients were placed prone on a stretcher. After skin disinfection, an injection of $2-5 \mathrm{~mL} 1 \%$ lidocaine just underneath the thoracolumbar fascia was administered 
using a $21 \mathrm{G} 40 \mathrm{~mm}$ needle. Volume was based on patient's weight and/or subcutaneous thickness around the tender point. Needle tip placement is just below the thoracolumbar fascia of the erector spinae muscle, ideally into or in close proximity to the tender point using a free hand technique, as previously published for ACNES or LACNES. ${ }^{24,25}$ Pain was then scored using a numerical rating scale (NRS, 0 [no pain] to 10 [worst possible pain]) immediately before and after a 10- to 15-minute observation period. If levels of pain were considerably lower (eg $>50 \%$ pain reduction) or absent by then, characteristics of the diagnosis were again communicated, and the patient was evaluated some 2-3 weeks later. If the pain had recurred at this first outpatient control, a combination of $2-5 \mathrm{~mL}$ of $1 \%$ lidocaine and $40 \mathrm{mg}$ of methylprednisolone was administered. When the effect of repetitive injections on experienced pain levels by patients was inadequate (eg $<50 \%$ pain reduction) or if patients declined ongoing injection therapy, patients were informed on alternative treatments including medication, physical therapy, manual therapy, transcutaneous electrical nerve stimulation (TENS), or (pulsed) radiofrequency therapy (pRF). If alternative therapy modalities were to no avail or denied, a surgical exploration was proposed. Specifics of the surgical procedure were communicated. If surgery was preferred, patients consented verbally and in writing to the operative procedure.

\section{Surgical procedure}

Localized surgical techniques as treatment for low back pain have been described in the early 1970 s by Rees. ${ }^{27}$ He described a percutaneous rhizolysis technique for supposed facet pain. Our surgical procedure is different since it requires a neurectomy of the lateral branch of the posterior rami instead of the medial branch, which innervates the zygapophysial joints. ${ }^{28,29}$

Patients were operated in a day-care setting. While lying in prone position, the point of maximal pain was again identified and marked. Once general anesthesia was administered, the thoracolumbar fascia was exposed via a transverse $\pm 5 \mathrm{~cm}$ long skin incision. The neurovascular bundle penetrating the subcutaneous fat was identified. The fascial window was widened and the nerve and all of its branches within a $5 \mathrm{~cm}$ radius were ligated and removed (Figure 2). Accompanying vascular structures were ligated or coagulated. The fascia and the remainder of the wound were closed in layers using absorbable suturing material. The patients received a control visit at the outpatient department $\sim 6$ weeks postoperatively.

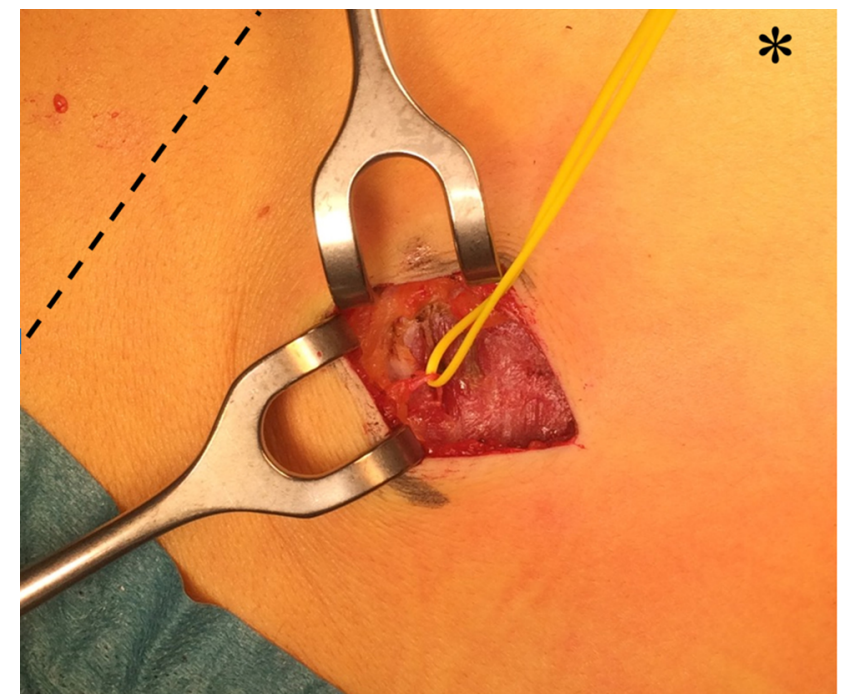

Figure 2 Peroperative view of a cutaneous branch of the posterior ramus of a thoracic nerve (loop) perforating the thoracolumbar fascia.

Notes: The transverse incision was made exactly over the pain point (marked with black ink), which was in the paravertebral region some 4-5 cm lateral to the midline (the dotted line). The asterisk indicates cranial in the prone patient.

\section{Data accrual}

A search of the hospital's electronic patient system was performed by the first author using a surgical diagnosis code that was exclusively assigned to abdominal wall and groin related pain syndromes. Data regarding age, gender, body mass index, diagnostic delay, etiology, NRS scores, DN4 scores, time of follow-up, date of being pain free, or possible recurrences were entered in a separate database. A 7-point version of the DN4, with $a \geq 3$ cutoff point suggestive of neuropathic pain was used in order to discriminate between neuropathic and nonneuropathic pain. ${ }^{23,30}$ NRS was used to score pain on a 0 (no pain) to 10 (worst possible pain) scale at baseline and during follow-up at the outpatient clinic. Treatment success was defined as $>50 \%$ pain reduction on the NRS scale. A final follow-up control to assess long-term clinical outcomes was done by a standardized telephone interview that included questions on current satisfaction and long-term complications. Level of satisfaction was determined as previously published (Box 2). ${ }^{24}$ Clinical success was defined as a verbal rating scale (VRS) of 1 or 2 ([very] satisfied), while a VRS of 3 was defined as an attenuated pain level. The therapy had failed if the patient reported a VRS of 4 or 5 .

\section{Statistical analysis}

All analyses were performed using the SPSS, version 21, for Windows. The sample size was determined pragmatically as a total of 14 patients who met our eligibility criteria were identified in our centers. Categorical variables were described 
Box 2 Level of satisfaction after treatment for ACNES using verbal rating scale

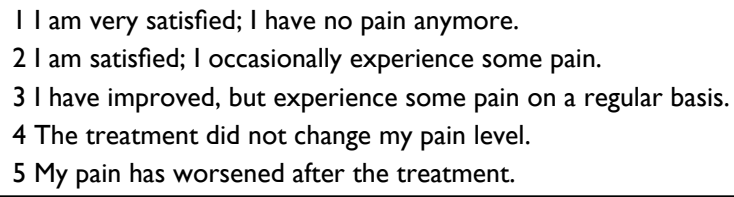

Notes: Reproduced from Boelens OB, Scheltinga MR, Houterman S, Roumen RM. Management of anterior cutaneous nerve entrapment syndrome in a cohort of 139 patients. Ann Surg. 201 I;254(6): 1054-1058. ${ }^{24}$

Abbreviation: ACNES, anterior cutaneous nerve entrapment syndrome.

as frequencies. Continuous data were tested for normality and are presented as mean \pm SD or median values (range) as appropriate. Changes in pain scores after lidocaine infiltration were evaluated using paired $t$-testing. A $P$-value of $<0.05$ was considered significant.

\section{Results}

\section{Baseline patient characteristics}

During a 4-year observation period, 14 patients (12 females; median age, 26 years; range 18-73 years) fulfilled inclusion criteria. Demographics are depicted in Table 1. All patients had undergone extensive earlier laboratory testing and imaging (ultrasound imaging, computer tomography, and/or magnetic resonance imaging scan) to exclude any visceral or mechanical underlying cause, mostly performed elsewhere. All showed no specific abnormal findings. All patients had a score of minimal 3 on the DN4 questionnaire (median 3, range 3-5) confirming a neuropathic pain syndrome. Interestingly, six of the patients had undergone an anterior neurectomy (success, $\mathrm{n}=3$ ) for ipsilateral ACNES at an earlier stage.

Location of the point of maximum tenderness was distributed between the inferior angle of scapula and the lowest costal margin. The point of maximal pain corresponded in half of the cases $(n=7)$ with the cutaneous branches of the posterior rami of the 12th thoracic spinal nerve. A positive pinch test was found in $86 \%$ (12/14). Combinations of various somatosensory disturbances were observed in all. There was no preponderance for left vs right. Two patients had a bilateral pain syndrome.

\section{Injection therapy $(n=\mid 4)$}

Interventions are depicted in Table 2 . All consented to a diagnostic maximal pain point infiltration using $2-5 \mathrm{~mL}$ of $1 \%$ lidocaine. Pre- and post-NRS scores (13 of 14 patients, $93 \%$ ) dropped from 8.0 (median, IQR 7.0-8.0) to 3.0 (median, IQR $1.5-3.5), P<0.001$. Ten of thirteen patients $(81 \%)$ reported a $>50 \%$ pain reduction. All 14 patients experienced partial or temporary relief, whereas 11 reported pain relief for days to
Table I Characteristics of patients with POCNES

\begin{tabular}{|l|l|}
\hline Patient characteristics & $\mathbf{n = 1 4}$ \\
\hline Age (range) & $26(18-73)$ \\
\hline Gender, F:M ratio & $12: 2$ \\
\hline Body mass index, kg/m² (SD) & $23(3)$ \\
\hline Diagnostic delay, months (range) of duration of pain & $22(5-48)$ \\
\hline Pain level at presentation (NRS, 0-I0), (IQR) & $8.0(7.0-8.0)$ \\
\hline DN4 (range, 0-7) & $3.0(3.0-5.0)$ \\
\hline Previous neurectomy for ACNES & 6 \\
\hline
\end{tabular}

Note: Data are presented as mean $\pm S D$, or median values with ranges.

Abbreviations: ACNES, anterior cutaneous nerve entrapment syndrome; DN4, Douleur Neuropathique 4; F, female; M, male; NRS, numerical rating scale; POCNES, posterior cutaneous nerve entrapment syndrome.

several weeks (Table 2). Just one patient opted to continue with incidentally repeated injections and her pain level was acceptable in the long term (13-month follow-up; VRS 2). Injection therapy was insufficient in the remaining 13 patients who all opted for subsequent alternative treatments.

\section{Surgery $(n=I I)$}

Eleven patients chose to undergo a neurectomy $(79 \%$, Table 2). At the 6-week postoperative evaluation, seven patients (64\%) were (very) satisfied (VRS 1 or 2) whereas three (27\%) reported attenuated pain levels (VRS 3). Surgery was unsuccessful in one patient (VRS 4). A VRS 5 was not scored. A $100 \%$ response rate of the eleven operated patients was attained in the long term (median 29 months, range 5-48), and seven (64\%) were satisfied (VRS 1-2). Surgery was unsuccessful in the remaining four (36\%, VRS 4). One initially successful patient (VRS 1) reported a recurrence of pain (VAS 4). No VRS 5 was scored.

\section{Nonsurgical treatment $(n=3)$}

Three patients declined surgery and underwent alternative therapies (repeated injection therapy, pRF therapy, and TENS). One patient was satisfied in the long term (13 months, VRS 2, injection therapy). However, the two others reported an unsuccessful result (VRS 4) of these therapies (pRF and TENS) after 13 and 37 months, respectively.

\section{Discussion}

The present case series reports on patients having a chronic localized (lower) back pain syndrome that is caused by an entrapped cutaneous branch of the posterior ramus of the thoracic spinal nerve, most commonly in the T11-12 area. The term POCNES has recently been introduced for this new pain entity. These patients report pain characteristics mimicking ACNES or LACNES, but the point of maximum pain is 
Table 2 Characteristics and treatment success of individual POCNES patients

\begin{tabular}{|c|c|c|c|c|c|c|c|c|c|c|c|c|}
\hline \multicolumn{5}{|c|}{ Patient characteristics } & \multicolumn{2}{|c|}{$\begin{array}{l}\text { Diagnostic } \\
\text { injection }\end{array}$} & \multicolumn{6}{|c|}{ Treatment and follow-up } \\
\hline $\mathbf{P t}$ & Age & Gender & Location & $\begin{array}{l}\text { Pain area in } \\
\text { corresponding } \\
\text { dermatome }\end{array}$ & $\begin{array}{l}\text { NRS } \\
\text { pre }\end{array}$ & $\begin{array}{l}\text { NRS } \\
\text { post }\end{array}$ & $\begin{array}{l}\text { Number of } \\
\text { injections }\end{array}$ & $\begin{array}{l}\text { Duration } \\
\text { of relief } \\
\text { postinjection }\end{array}$ & Neurectomy & $\begin{array}{l}\text { Pain } \\
\text { specialist }\end{array}$ & $\begin{array}{l}\text { Final } \\
\text { VRS }^{\mathbf{a}}\end{array}$ & $\begin{array}{l}\text { Duration } \\
\text { (months) }\end{array}$ \\
\hline 1 & 19 & $M$ & Left & T8 & 7 & 2 & 3 & Days & $Y$ & $N$ & 2 & 20 \\
\hline 2 & 21 & $\mathrm{~F}$ & Right & TI2 & 7 & 0 & I & Weeks & $\mathrm{Y}$ & $\mathrm{N}$ & 2 & 20 \\
\hline 3 & 50 & $M$ & Right & TI2 & 8 & 4 & 2 & Days & $\mathrm{Y}$ & $\mathrm{N}$ & 4 & 31 \\
\hline 4 & 18 & $\mathrm{~F}$ & Right & TI2 & 8 & 1 & 1 & Days & $Y$ & $\mathrm{~N}$ & 4 & 33 \\
\hline 5 & 24 & $\mathrm{~F}$ & Right & TIO & 7 & 3 & 2 & Hours & $Y$ & $\mathrm{~N}$ & 4 & 36 \\
\hline 6 & 18 & $\mathrm{~F}$ & Bilateral & T7 & 9 & 0 & 2 & Days & $Y$ & $\mathrm{~N}$ & I & 27 \\
\hline 7 & 26 & $\mathrm{~F}$ & Right & TI2 & 7 & 3 & 3 & Days & $Y$ & $\mathrm{~N}$ & 1 & 48 \\
\hline 8 & 48 & $F$ & Left & T8 & 8 & 3 & 2 & Days & $Y$ & $N$ & I & 16 \\
\hline 9 & 46 & $F$ & Left & TI2 & 6 & 3 & 2 & Days & $Y$ & $\mathrm{~N}$ & 2 & 5 \\
\hline 10 & 20 & $\mathrm{~F}$ & Left & T8 & 8 & 4 & 2 & Days & $Y$ & $\mathrm{~N}$ & 2 & 47 \\
\hline 11 & 28 & $\mathrm{~F}$ & Left & TII & 7 & 3 & I & Hours & $\mathrm{N}$ & $Y$ & 4 & 13 \\
\hline 12 & 43 & $\mathrm{~F}$ & Bilateral & TI2 & - & - & 2 & Weeks & $\mathrm{N}$ & $Y$ & 4 & 37 \\
\hline 13 & 26 & $F$ & Right & TI2 & 8 & 5 & 2 & Hours & $Y$ & $\mathrm{~N}$ & \begin{tabular}{|l|}
4 \\
\end{tabular} & 32 \\
\hline 14 & 73 & $F$ & Left & TII & 9 & 2 & 9 & Weeks & $N$ & $N$ & 2 & 13 \\
\hline
\end{tabular}

Notes: NRS pre/post injection. - indicates missing data. a'Long-term success at follow-up is defined as attaining final VRS score of I or 2 (corresponding with $>50 \%$ pain reduction, $\mathrm{n}=8$ ) after receiving one or more interventions.

Abbreviations: N, no; NRS, numerical rating scale; POCNES, posterior cutaneous nerve entrapment syndrome; Pt, patient ID number; VRS, verbal rating scale; Y, yes.

located at the lower paravertebral region rather than in the ventral or lateral portions of the trunk or abdomen. Aim of the present study was to describe clinical presentation, differential diagnosis, and management of a series of these patients. A simple step-up treatment regimen including injections and neurectomy resulted in a long-term pain relief in more than half $(57 \%)$ of these patients. It should be appreciated that the median time of duration of our patients having this undiagnosed (lower) back pain syndrome $\sim 2$ years before the diagnosis POCNES was considered. Based on a characteristic patient's history (localized pain) and physical examination (point of maximal pain in an area having somatosensory disturbances), this novel pain syndrome should be considered in the differential diagnosis of each patient with CBP in the presence of overlying somatosensory disturbances.

To our knowledge, this is the first case-series reporting on a pain syndrome possibly caused by entrapment of cutaneous branches of posterior rami of thoracic nerves. In recent years, an increasing number of studies were published on an anterior variant of entrapped intercostal nerves (ACNES). ${ }^{17,18,21,24,31}$ However, reflecting on anatomy, it should be realized that the thoracic nerves also have posterior branches. Other groups reported on two patients having a pain entity due to possible entrapment of lateral branches of intercostal nerves. ${ }^{32,33} \mathrm{~A}$ larger case series on this entity (LACNES) was published recently. ${ }^{25}$ The first case report on a posterior version of ACNES with involvement of posterior cutaneous branches of thoracic nerves resulting in severe lower back pain appeared in 2017. ${ }^{11}$ It is our understanding that, although patients present with pain at different locations (eg, anteriorly, laterally, or posteriorly), the three pain syndromes (ACNES, LACNES, and POCNES) have a high degree of overlap in signs and symptoms at physical examination and history and may be different expressions of a similar underlying thoracic spinal nerve pain syndrome.

Current detailed textbook descriptions of the anatomy of the thoracic dorsal rami vary and are limited. ${ }^{34-36}$ Dorsal or posterior rami are thought to divide in medial and lateral branches, while the latter branches into a medial and lateral twig (Figure 1). Medial branches innervate the zygapophysial joints and the multifidus muscle, while lateral branches innervate the iliocostalis and longissimus muscle and overlying skin. ${ }^{28,29}$ The main lateral branch runs caudally, laterally, and dorsally underneath the longissimus muscles and descends approximately two vertebral segments caudally before it pierces the thoracolumbar fascia. It than divides in a medial (sometimes referred to as "intermediate") and lateral cutaneous branch providing skin sensation ${ }^{28,29,37}$ This rather complex and possibly variable anatomical course of dorsal rami may explain why this cause for chronic localized back pain has been overlooked until now, as is often the case in other neuropathic abdominal wall pain syndromes. ${ }^{25,38,39}$ The first POCNES case report raised awareness regarding this particular presentation of symptoms and resulted in the identification of more cases over the following years. ${ }^{11}$ 
The description of a novel syndrome is greatly aided if a clear list of criteria regarding history and physical examination is identified. Pivotal is pain that is characterized by a constant and predictable site of local tenderness situated in the lower back just lateral to the spinal process in the paravertebral region. Moreover, a fingertip small point of maximum pain may be present within this painful area. Upper body bending or lateroflexion might elicit a recognizable pain. At this tender area, skin sensation is disturbed (hypo- or hyperesthesia, altered cold perception) when tested using a gently touching swab and an alcohol soaked gauze. A positive pinch test at the site of maximal pain is often present. ${ }^{24,26}$ Additional blood tests and imaging are consistently normal. If these criteria are present, a diagnostic injection at the maximum pain point should be offered. A (temporary) response to a local diagnostic tender point infiltration using lidocaine contributes to a presumed diagnosis POCNES.

In the present case series, $2-5 \mathrm{~mL}$ of local anesthetics were administered, depending on patient's weight and/or subcutaneous thickness around the tender point. We are aware that in the field of anesthesiology, even smaller volumes of local anesthetic agents for peripheral nerve blockade may be preferred. It also has been shown that larger volumes may lead to increased rates of adverse events. ${ }^{40}$ Furthermore, uncontrolled spreading of relatively large volumes of local anesthetic agents may reduce diagnostic specificity. ${ }^{41,42} \mathrm{~A}$ possible option would include local electrical nerve stimulation under ultrasound guidance as performed with $\mathrm{pRF}$, since this approach may allow for a more appropriate identification of the affected nerve. Using a closed electrical circuit, proper localization of the nerve is achieved by sensory stimulation. Sensations such as paresthesia, numbness, or the recognizable pain should occur at $<0.5 \mathrm{~V}$ if the needle's position is correct. ${ }^{43}$ This technique was not used in the presented case series but may potentially diminish low volumes of local anesthetics for diagnostic nerve blockades as also observed in ACNES patients. ${ }^{44}$ In our series, 11 of 14 patients reported a temporary pain relief of days to weeks after the diagnostic injection. Although possibly different from what may be observed in ACNES patients, limited short-term efficacy of injection therapy in POCNES justified a surgical neurectomy once debilitating pain symptoms persist.

The differential diagnosis of POCNES is extensive and includes thoracic radicular pain, thoracic facet pain, and the thoracolumbar syndrome (TLS; also known as Maigne's syndrome). ${ }^{6,74}$ Thoracic radicular pain is characterized by a locoregional pain that radiates into a specific dermatome. ${ }^{7}$ In contrast, patients with thoracic facet pain may present with a variety of symptoms including unilateral and/or bilateral low back pain, tenderness of zygapophysial joints (facet) or transverse processes upon palpation, and pain that aggravated with lateral flexion and/or rotation. ${ }^{46,47}$ This diagnosis of facet pain should be considered if patients report paravertebral pain that worsens by prolonged standing, extending, or rotating the spinal column. Pain is usually radiating into a somewhat larger area whereas specific point of maximum pain is absent. Moreover, the pain concerns overlapping multiple dermatomes. ${ }^{7}$ As in POCNES, the diagnosis is usually established by local anesthetic blocks. ${ }^{7}$

Alternatively, the TLS is defined as a localized thoracolumbar backache caused by irritation of the facet joints resulting in pain that irradiates toward the iliac crest area corresponding with cutaneous branches of T12 to L2. ${ }^{6}$ The associated back pain is occasionally accompanied by sensory disturbances and trigger points that are almost solely situated over the iliac crest, usually at least 7 or $8 \mathrm{~cm}$ away from the midline..$^{48,49}$ The anatomical pattern of innervation explains why pain arising from facet joints projects itself as referred pain around the iliac crest. This theory can also be reversed with a local entrapment neuropathy at the osteofibrous tunnel near the iliac crest in fact reflecting irritation of facet joints localized higher up. It may be argued that the diagnoses POCNES and TLS share certain symptoms. However, POCNES is caused by entrapment of lateral branches of the dorsal ramus of T7-12 whereas TLS emanates only from T12 to $\mathrm{L} 2$ and refers to the superior clunial nerves ${ }^{45}$ In addition, the maximum pain site in POCNES is located just (3-5 $\mathrm{cm})$ lateral to the spinal process in the paravertebral region instead of more laterally at the iliac crest as in TLS. Therefore, POCNES is hypothesized to be a new clinical entity due to its specific nature and distribution pattern.

The present case series does not allow for a speculation on the nature of risk factors. However, 6 of 14 POCNES patients had previously undergone an anterior neurectomy for ipsilateral ACNES. Time between the first onset of ACNES and the diagnosis of POCNES in these cases was 12 months (median, range 8-32). If entrapment of an intercostal nerve occurs, the most distal portion (anterior) is preferentially at risk. ${ }^{19}$ However, nerve lesions may cause molecular changes in nociceptive neurons ( $\mathrm{C}$-fibers) and nonnociceptive neurons (A $\delta$ - or $A \beta$-fibers) by releasing growth factors. ${ }^{50}$ These growth factors can result in hyperexcitability of initially normal surrounding nerves. This dynamic process could also spread toward more proximal portions of the originally affected nerve lesion. ${ }^{51}$ It is hypothesized that this mechanism could lead to "irritation" along the entire anatomical nerve tract and thereby even affect the posterior rami of the thoracic nerve. 
Indeed, substantial numbers of ACNES patients having anterior abdominal pain report flank and even back pain reflecting involvement of more proximal portions of the thoracic spinal nerve (Mol et al, Department of Surgery, Máxima Medical Center, unpublished data, December 2018)..$^{52}$ Unfortunately, data on earlier tests of back pain in these six ACNES patients were not obtained. Nevertheless, the present findings suggest that each patient with intercostal neuralgia should undergo an examination of the abdomen, flank, as well as lower back to determine the presence of somatosensory disturbances and specific tender points along the entire thoracic spinal nerve.

This current study harbors flaws including its retrospective character and a limited number of patients who were analyzed in two tertiary referral centers precluding generalizability. As tertiary referral centers for abdominal wallrelated pain, results may not immediately be extrapolated to an average clinical practice due to potential referral and selection bias such as by indication. As a consequence, this novel syndrome may only be diagnosed in a small number of patients having spinal pain. However, this paper contributes to the awareness and possible treatment of patients who would otherwise remain burdened by their pain. It is also appreciated that tests such as laser evoked potentials, nerve biopsies, and quantitative sensory testing objectively determining somatosensory disturbances were not used. ${ }^{14}$ Nevertheless, we feel confident that our patients were having characteristic signs and symptoms associated with affected posterior branches of thoracic nerves as also reported in similar syndromes such as ACNES and LACNES. ${ }^{24,25}$ Our conviction is strengthened by the observation that seven of eleven patients receiving a local neurectomy of the posterior cutaneous nerve branch reported a complete and long-lasting pain relief.

\section{Conclusion}

A POCNES should be considered in patients with chronic localized back pain. Specifics in the patient's history and simple bedside tools may aid in determining whether the pain is related to entrapment of cutaneous branches of posterior rami of the thoracic nerves. A treatment regimen including injections and neurectomy may offer long-term pain relief in over half of these patients.

\section{Disclosure}

The authors report no conflicts of interest in this work.

\section{References}

1. Kamper SJ, Henschke N, Hestbaek L, Dunn KM, Williams CM. Musculoskeletal pain in children and adolescents. Braz J Phys Ther. 2016;20(3):275-284.
2. Hoy D, March L, Brooks P, et al. The global burden of low back pain: estimates from the Global Burden of Disease 2010 study. Ann Rheum Dis. 2014;73(6):968-974.

3. GBD 2015 Disease and Injury Incidence and Prevalence Collaborators. Global, regional, and national incidence, prevalence, and years lived with disability for 310 diseases and injuries, 1990-2015: a systematic analysis for the Global Burden of Disease Study 2015. Lancet. 2016;388(10053):1545-1602.

4. Maher C, Underwood M, Buchbinder R. Non-specific low back pain. Lancet. 2017;389(10070):736-747.

5. Deyo RA, Weinstein JN. Low back pain. N Engl J Med. 2001;344(5): 363-370.

6. Maigne R. [The thoraco-lumbar junction syndrome. Low-back pain, pseudo-visceral pain, pseudo-hip pain and pseudo-pubic pain (author's transl)]. Sem Hop. 1981;57(11-12):545-554.

7. van Kleef M, Stolker RJ, Lataster A, Geurts J, Benzon HT, Mekhail N. 10. Thoracic pain. Pain Pract. 2010;10(4):327-338.

8. Hartvigsen J, Hancock MJ, Kongsted A, et al. What low back pain is and why we need to pay attention. Lancet. 2018;391(10137): 2356-2367.

9. da C Menezes Costa L, Maher CG, Hancock MJ, McAuley JH, Herbert RD, Costa LO. The prognosis of acute and persistent low-back pain: a meta-analysis. CMAJ. 2012;184(11):E613-E624.

10. Foster NE, Anema JR, Cherkin D, et al. Prevention and treatment of low back pain: evidence, challenges, and promising directions. Lancet. 2018;391(10137):2368-2383.

11. Boelens OB, Maatman RC, Scheltinga MR, van Laarhoven K, Roumen RM. Chronic localized back pain due to posterior cutaneous nerve entrapment syndrome (POCNES): a new diagnosis. Pain Phys. 2017;20(3):E455-E458.

12. Costigan M, Scholz J, Woolf CJ. Neuropathic pain: a maladaptive response of the nervous system to damage. Annu Rev Neurosci. 2009;32:1-32.

13. Jensen TS, Finnerup NB. Allodynia and hyperalgesia in neuropathic pain: clinical manifestations and mechanisms. Lancet Neurol. 2014;13(9):924-935.

14. Graven-Nielsen T, Arendt-Nielsen L. Assessment of mechanisms in localized and widespread musculoskeletal pain. Nat Rev Rheumatol. 2010;6(10):599-606.

15. Rasmussen PV, Sindrup SH, Jensen TS, Bach FW. Symptoms and signs in patients with suspected neuropathic pain. Pain. 2004;110(1-2):461-469.

16. Cruccu G, Truini A. Tools for assessing neuropathic pain. PLoS Med. 2009;6(4):e1000045.

17. Boelens OB, van Assen T, Houterman S, Scheltinga MR, Roumen RM. A double-blind, randomized, controlled trial on surgery for chronic abdominal pain due to anterior cutaneous nerve entrapment syndrome. Ann Surg. 2013;257(5):845-849.

18. van Assen T, Boelens OB, van Eerten PV, Perquin C, Scheltinga MR, Roumen RM. Long-term success rates after an anterior neurectomy in patients with an abdominal cutaneous nerve entrapment syndrome. Surgery. 2015;157(1):137-143.

19. Applegate WV, Buckwalter NR. Microanatomy of the structures contributing to abdominal cutaneous nerve entrapment syndrome. $J \mathrm{Am}$ Board Fam Pract. 1997;10(5):329-332.

20. Applegate W. Abdominal cutaneous nerve entrapment syndrome (ACNES): a commonly overlooked cause of abdominal pain. Perm J. 2002;6(3):20-27.

21. Boelens OB, Scheltinga MR, Houterman S, Roumen RM. Randomized clinical trial of trigger point infiltration with lidocaine to diagnose anterior cutaneous nerve entrapment syndrome. Br J Surg. 2013;100(2):217-221.

22. Loos MJ, Scheltinga MR, Roumen RM. Surgical management of inguinal neuralgia after a low transverse Pfannenstiel incision. Ann Surg. 2008;248(5):880-885.

23. van Seventer R, Vos C, Meerding W, et al. Linguistic validation of the DN4 for use in international studies. Eur J Pain. 2010;14(1):58-63. 
24. Boelens OB, Scheltinga MR, Houterman S, Roumen RM. Management of anterior cutaneous nerve entrapment syndrome in a cohort of 139 patients. Ann Surg. 2011;254(6):1054-1058.

25. Maatman RC, Papen-Botterhuis NE, Scheltinga MRM, Roumen RMH. Lateral cutaneous nerve entrapment syndrome (LACNES): a previously unrecognized cause of intractable flank pain. Scand J Pain. 2017;17:211-217.

26. Carnett J. Intercostal neuralgia as a cause of abdominal pain and tenderness. Surg Gynecol Obstet. 1926;42:625-632.

27. Rees W. Multiple bilateral subcutaneous rhizolysis of segmental nerves in the treatment of the intervertebral disc syndrome. Ann Gen Pract. 1971;26:126-127.

28. Shuang F, Hou SX, Zhu JL, et al. Clinical anatomy and measurement of the medial branch of the spinal dorsal ramus. Medicine (Baltimore) 2015;94(52):e2367.

29. Bogduk N, Wilson AS, Tynan W. The human lumbar dorsal rami. J Anat. 1982;134(Pt 2):383-397.

30. Bouhassira D, Attal N, Alchaar H, et al. Comparison of pain syndromes associated with nervous or somatic lesions and development of a new neuropathic pain diagnostic questionnaire (DN4). Pain. 2005;114(1-2):29-36.

31. Siawash M, Maatman R, Tjon A Ten W, van Heurn E, Roumen R, Scheltinga M. Anterior neurectomy in children with a recalcitrant anterior cutaneous nerve entrapment syndrome is safe and successful. J Pediatr Surg. 2017;52(3):478-480.

32. Sharf M, Shvartzman P, Farkash E, Horvitz J. Thoracic lateral cutaneous nerve entrapment syndrome without previous lower abdominal surgery. J Fam Pract. 1990;30(2):211214.

33. Peleg R, Gohar J, Koretz M, Peleg A. Abdominal wall pain in pregnant women caused by thoracic lateral cutaneous nerve entrapment. Eur J Obstet Gynecol Reprod Biol. 1997;74(2):169-171.

34. Johnston HM. The cutaneous branches of the posterior primary divisions of the spinal nerves, and their distribution in the skin. J Anat Physiol. 1908;43(Pt 1):8085-8092.

35. Lazorthes G, Zadeh J, Galy E, Roux P. [The cutaneous field of the posterior branches of the cervical nerves and first thoracic nerves. Revision of Déjerine's plan]. Bull Assoc Anat. 1986;70(210): 37-38.

36. Williams PL, Warwick R, Dyson M, Bannister LH. Gray's Anatomy. 37th ed. Edinburgh: Churchill Livingstone; 1989.

37. Maigne JY, Maigne R, Guérin-Surville H. Upper thoracic dorsal rami: anatomic study of their medial cutaneous branches. Surg Radiol Anat. 1991;13(2):109-112.

38. Lindsetmo RO, Stulberg J. Chronic abdominal wall pain - a diagnostic challenge for the surgeon. Am J Surg. 2009;198(1):129-134.
39. Srinivasan R, Greenbaum DS. Chronic abdominal wall pain: a frequently overlooked problem. Practical approach to diagnosis and management. Am J Gastroenterol. 2002;97(4):824-830.

40. Barrington MJ, Kluger R. Ultrasound guidance reduces the risk of local anesthetic systemic toxicity following peripheral nerve blockade. Reg Anesth Pain Med. 2013;38(4):289-297.

41. North RB, Kidd DH, Zahurak M, Piantadosi S. Specificity of diagnostic nerve blocks: a prospective, randomized study of sciatica due to lumbosacral spine disease. Pain. 1996;65(1):77-85.

42. Furman MB, Lee TS, Mehta A, Simon JI, Cano WG. Contrast flow selectivity during transforaminal lumbosacral epidural steroid injections. Pain Physician. 2008;11(6):855-861.

43. Ford DJ, Pither C, Raj PP. Comparison of insulated and uninsulated needles for locating peripheral nerves with a peripheral nerve stimulator. Anesth Analg. 1984;63(10):925-928.

44. Maatman RC, Steegers MAH, Kallewaard JW, Scheltinga MRM, Roumen RMH. Pulsed radiofrequency as a minimally invasive treatment option in anterior cutaneous nerve entrapment syndrome: a retrospective analysis of 26 patients. J Clin Med Res. 2018;10(6):508-515.

45. Proctor D, Dupuis P, Cassidy JD. Thoracolumbar syndrome as a cause of low-back pain: a report of two cases. J Can Chiropr Assoc. 1985;29(2):71-73

46. Dreyfuss P, Tibiletti C, Dreyer SJ. Thoracic zygapophyseal joint pain patterns. A study in normal volunteers. Spine (Phila Pa 1976). 1994;19(7):807-811.

47. Fukui S, Ohseto K, Shiotani M. Patterns of pain induced by distending the thoracic zygapophyseal joints. Reg Anesth. 1997;22(4):332-336.

48. Maigne JY, Lazareth JP, Maigne R. [Anatomical study of the cutaneous innervation of the lumbosacral region. Application to the physiopathology of certain lumbalgias]. Rev Rhum Mal Osteoartic. 1988;55(2):107-111.

49. Maigne JY, Maigne R. Trigger point of the posterior iliac crest: painful iliolumbar ligament insertion or cutaneous dorsal ramus pain? An anatomic study. Arch Phys Med Rehabil. 1991;72(10):734-737.

50. Wu G, Ringkamp M, Hartke TV, et al. Early onset of spontaneous activity in uninjured $\mathrm{C}$-fiber nociceptors after injury to neighboring nerve fibers. J Neurosci. 2001;21(8):RC140.

51. Miranda J, Lamana SM, Dias EV, Athie M, Parada CA, Tambeli CH. Effect of pain chronification and chronic pain on an endogenous pain modulation circuit in rats. Neuroscience. 2015;286:37-44.

52. Cousins MJ, Bridenbaugh PO, editors. Neural Blockade in Clinical Anesthesia and Management of Pain. 3rd ed. Philadelphia: LippincottRaven; 1998.

\section{Journal of Pain Research}

\section{Publish your work in this journal}

The Journal of Pain Research is an international, peer reviewed, open access, online journal that welcomes laboratory and clinical findings in the fields of pain research and the prevention and management of pain. Original research, reviews, symposium reports, hypothesis formation and commentaries are all considered for publication.

\section{Dovepress}

The manuscript management system is completely online and includes a very quick and fair peer-review system, which is all easy to use. Visit http://www.dovepress.com/testimonials.php to read real quotes from published authors. 